\title{
EXPRESSÃO DE MOLÉCULAS IMUNORREGULADORAS EM RINS NÃO-FUNCIONANTES COM REJEIÇÃO AGUDA
}

\author{
Detection of immunoregulator molecules inside non-functional kidney allografts \\ upon a rejection episode.
}

\author{
Erika Lamkowski Naka1, Viviane Campos Ponciano, Erika Beviláquia Rangel', Marcos Antônio Cenedeze, \\ Alvaro Pacheco-Silva ${ }^{1}$, Niels Olsen Saraiva Câmara ${ }^{1,2}$
}

\begin{abstract}
RESUMO
Introdução: Tim-3 é uma proteína de membrana com função inibitória, presente em linfócitos Th1. Seu ligante recentemente identificado, a galectina-9, é expresso em alguns subtipos de linfócitos, e também pode ser induzido por citocinas inflamatórias em células endoteliais e fibroblastos. Juntamente com as células T CD4+CD25+, essas moléculas exercem uma função reguladora da resposta imune. O fator de transcrição FOXP3 está relacionado aos linfócitos T reguladores CD4+CD25+. Objetivo: Avaliar a presença de moléculas relacionadas à resposta imune reguladora intra-enxerto renal durante episódio de rejeição. Material e Métodos: Os níveis de RNA mensageiro para moléculas representativas da resposta imune reguladora (Tim-3, galectina-9 e FOXP3) e da resposta imune citotóxica (perforina, granzima B e interferon- $\gamma$ ) foram quantificados pelo método de reação em cadeia da polimerase em 24 amostras de produtos de enxertectomia, com os seguintes diagnósticos: rejeição aguda não-vascular $(n=5)$, rejeição aguda vascular (n=14) e perda de causa não-imune (n=5, como controle). Resultados: A diferença encontrada entre as medianas dos grupos controle e de rejeição aguda vascular foi estatisticamente significante para todas as moléculas avaliadas: $\mathrm{p}=0,024$ para galectina- $9, \mathrm{p}=0,008$ para Tim $3, \mathrm{p}=0,005$ para FOXP3, $\mathrm{p}=0,008$ para perforina e interferon- $\gamma$, e p $=0,003$ para granzima B. Conclusão: Esse padrão sugere que o desenvolvimento da resposta imune é um evento dinâmico, com expressão de moléculas e recrutamento de células com funções diferentes, citopática e reguladora.
\end{abstract}

Descritores: Transplante de Rim, Rejeição de Enxerto, Tolerância Imunológica

\section{Instituição: \\ 1 Laboratório de Imunologia Clínica e Experimental (Disciplina de Nefrologia) da Universidade de São Paulo, São Paulo / SP - Brasil. \\ 2 Laboratório de Imunologia de Transplante (Departamento de Imunologia) da Universidade de São Paulo, São Paulo /SP - Brasil}

Correspondência:

Niels Olsen Saraiva Câmara, M.D.,

Departamento de Imunologia, Instituto de Ciências Biomédicas IV, Universidade de São Paulo

Rua Prof. Lineu Prestes, 1730 - CEP 05508-900 - São Paulo / SP - Brasil

Tel.: (5511) - 3091-7388

Fax: (5511) - 3091-7224

E-mail: niels@icb.usp.br

Apoio:

Este trabalho tem o apoio da FAPESP (Fundação de Apoio à Pesquisa do Estado de São Paulo), projeto número 04/08226-9, 04/08311-6 e CAPES.

\section{INTRODUÇÃO:}

No transplante, o órgão enxertado é fonte de diversos antígenos, os quais são reconhecidos como não-próprios pelo sistema imunológico. A rejeição aguda acontece quando uma resposta contra esses antígenos estranhos se desenvolve. ${ }^{1}$

A homeostase do sistema imune depende de um equilíbrio constante entre uma resposta pró-inflamatória necessária para a defesa do organismo contra antígenos estranhos e os mecanismos de regulação dessa resposta, importantes para o controle da mesma. O desenvolvimento de algumas doenças auto-imunes parece estar relacionado à quebra desse equilíbrio. ${ }^{2}$ Essa regulação ocorre de diversas maneiras, como, por exemplo, por barreiras físicas, anergia, deleção clonal ou pela ação de células reguladoras. ${ }^{3}$ Todos esses mecanismos agindo isoladamente ou em conjunto, são capazes de impedir uma resposta imune exagerada ou contra antígenos próprios.

A molécula Tim-3 e seu ligante recém descoberto, a galectina-9, fazem parte dessa resposta imune reguladora. O Tim-3 é uma molécula de superfície, expressa predominantemente em linfócitos da resposta celular do tipo Th1, produtores de citocinas próinflamatórias. ${ }^{4}$ A galectina-9 pertence a uma família de lecitinas endógenas com afinidade para alguns resíduos específicos 
de carboidratos. ${ }^{5}$ Diferentes moléculas dentro dessa família desempenham papéis imunológicos distintos relacionados tanto à atividade pró-inflamatória quanto reguladora. ${ }^{6}$ A galectina- 9 é encontrada em linfócitos $\mathrm{T}$ ativados ${ }^{7}$ e sua expressão pode ser induzida em outras células, como fibroblastos e células endoteliais, pela ação do IFN- $\gamma^{8,9}$ A ligação do Tim-3 com a galectina-9 resulta em morte dos linfócitos Th1, provavelmente por um mecanismo que envolva necrose-apoptose..$^{10}$ A expressão aumentada de galectina-9 sob estímulo pró-inflamatório sugere uma auto-regulação da resposta Th1, visto que o IFN- $\gamma$ é produzido principalmente por esse subtipo de linfócitos.

O fator de transcrição FOXP3 é encontrado em células T reguladoras CD4+CD25+ naturais provenientes do timo. ${ }^{11}$ Essas células são capazes de inibir a atividade de outros linfócitos, por mecanismos ainda não completamente esclarecidos, mas que aparentemente envolvem a regulação transcricional do gene da IL-2. ${ }^{12}$ Além da presença nas células Treg de origem tímica, a expressão de FOXP3 também pode ser induzida em linfócitos CD4+CD25- na periferia, sob estímulo de algumas citocinas, como o TGF- $\beta .^{13,14}$ Em camundongos, a indução da expressão de FOXP3 confere aos linfócitos uma função reguladora semelhante às Tregs naturais, ${ }^{15,16}$ porém, foi demonstrado recentemente em humanos que esse fator de transcrição pode estar presente em linfócitos T ativados, não reguladores. ${ }^{17}$

O papel desses mecanismos reguladores no contexto do transplante de órgãos não está totalmente esclarecido. Estudos experimentais com células Tregs demonstraram uma ação protetora ao enxerto, possibilitando o desenvolvimento de um estado de tolerância imunológica. ${ }^{18}$ Porém, como esses mecanismos imunorreguladores se comportam durante um episódio de rejeição aguda ainda precisa ser elucidado. Dados anteriores do nosso grupo demonstraram maior detecção das moléculas FOXP3 ${ }^{19}$ e TIM3 ${ }^{20}$ dentro do enxerto renal durante um episódio de rejeição, e esse aumento foi maior em rejeições mais graves. Todavia, essas alterações quantitativas podem não se refletir numa melhora da função. $\mathrm{O}$ objetivo do presente estudo foi analisar em conjunto a presença de moléculas indicativas de resposta imuno-reguladora com moléculas indicativas da resposta citopática.

\section{MATERIAL E MÉTODOS}

\section{Desenho do Estudo}

Foram estudadas 24 amostras de produtos de enxertectomias renais. Todas foram submetidas à análise histológica por um patologista, e o diagnóstico de rejeição foi dado seguindo os critérios estabelecidos pela classificação de Banff $97 .{ }^{21} \mathrm{O}$ grupo denominado rejeição aguda não-vascular (RANV, n=5) corresponde aos graus Ia, Ib e IIa, e o grupo rejeição aguda vascular (RAV, n=14) aos graus IIb e III. Essas amostras compreendem tanto casos que não responderam ao tratamento imunossupressor, como rejeições agudas sobrepostas à nefropatia crônica após redução da imunossupressão com o retorno do paciente ao tratamento dialítico. A nefropatia crônica do enxerto estava presente em duas amostras do grupo RANV e em nove amostras do grupo RAV. Foram usados como controle produtos de enxertectomia com perda devido à falha técnica (trombose). Esse grupo foi denominado de perda por causa não-imune (PCNI, $\mathrm{n}=5$ ). Foram analisadas também quatro amostras de biópsia protocolar normal, porém, não houve nessas amostras amplificação dos transcritos das moléculas FOXP3 e Galectina-9, não sendo, portanto, um controle válido para a técnica utilizada. Todas as amostras foram mantidas em RNAlater à temperatura de $-80^{\circ} \mathrm{C}$. Esse trabalho foi submetido e aprovado pelo Comitê de Ética.

\section{Quantificação relativa do mRNA por RT-PCR em tempo real}

O RNA total foi purificado por extração pelo TriZol (Invitrogen, Califórnia, EUA), de acordo com as instruções do fabricante. Após extração, as amostras foram tratadas com DNAse (Promega, WI, EUA) para a remoção do DNA genômico. A transcrição reversa do RNA foi obtida usando primers oligo-dT (Invitrogen, Califórnia, EUA) e MMLV (moloney murine leukemia virus) como enzima de transcriptase reversa (Promega, WI, EUA). O cDNA foi amplificado com ABI PRISM 7700 Sequence Detection System (PerkinElmer, Norwalk, CT) usando o método de 5'nuclease (TaqMan, Applied Biosystems, Foster City, EUA). Todos os primers foram fornecidos pela Applied Biosystems (Foster City, EUA): ciclofilina A, galectina-9 e FOXP3 por Assays-ondemand TM gene expression assays; GAPDH, Tim-3, granzima $\mathrm{B}$, perforina e IFN-gama por Assays-by-Design Service for Gene Expression Assays. Em todas as sondas foi utilizado FAM como corante. As seqüências dos primers e probes obtidos por Assaysby-Design foram Tim-3: FAM probe, 5'-CCAGGCATAATGAATG - 3'; forward primer, 5'-TGCTGCCGGATCCAAATC-3'; reverse primer, 5'-GGTTTGATGACCAACTTCAGGTTAA3'; IFN- $\gamma$ : FAM probe, 5'-AGGAGAGTGACAGAAAA- 3'; forward primer, 5'-TTAGGCATTTTGAAGAATTGGAAAG- 3'; reverse primer, 5'-GGAGACAATTTGGCTCTGCATTAT- 3'. perforin: FAM probe, 5'-TCGAGGCCCAGGTCA-3'; forward primer, 5'-GAGGTGGAGGACTGCCTGACT-3'; reverse primer, 5'-CTGCCGTGGATGCCTATGT-3'. granzima B: FAM probe, 5'-AGGTGAAGCCAGGCA-3'; forward primer, 5'-CCCTCAGGCTACCTAGCAACAA-3'; reverse primer, 5'CCGGCCACACTGCATGT-3'. As seqüências dos primers e probes por Assays-on-demand não são fornecidos pelo fabricante. Os níveis de RNA mensageiro (mRNA) dos genes de interesse foram todos uniformizados inicialmente para a expressão do gene endógeno (ciclofilina A) e, após, de forma relativa a um calibrador (média aritmética dos valores de $\mathrm{Ct}$ da Ciclofilina $\mathrm{A}$ ). Os resultados foram expressos como $2^{\text {-(DDCt)}}$, onde DDCt corresponde a $\left(\mathrm{Ct}_{\mathrm{GENE} \text { DE }}\right.$ INTERESSE $\left.-\mathrm{Ct}_{\text {CICLO}}\right)$ amostra/( $\left.\mathrm{Ct}_{\text {GENE DE INTERESSE }}-\mathrm{Ct}_{\mathrm{CICLO}}\right)$ referência.

\section{Análise estatística}

Foram usados testes t de Student ou Mann-Whitney U-test, quando apropriado, para a comparação das variáveis contínuas. As variáveis categóricas foram analisadas pelo teste exato de Fisher. Valores abaixo de 0,05 foram considerados estatisticamente significantes. Para a analise de correlação foi utilizado o coeficiente de correlação de Pearson.

\section{RESULTADOS}

\section{Características dos pacientes estudados}

Dos pacientes estudados, 14 (58\%) eram do sexo masculino e dez (42\%) do sexo feminino. Doze (50\%) receberam transplante de doador falecido. A idade média dos pacientes foi de 34,2 $\pm 11,9$ anos para PCNI, 35,6 $\pm 11,4$ anos para RACNV e 36,7 $\pm 11,1$ anos para RAV. 
Os sete pacientes com diagnóstico de rejeição aguda resistente ao tratamento (três no grupo RACNV e cinco no grupo RAV) encontravam-se em uso de esquema triplo de imunossupressão: um inibidor da calcineurina (ciclosporina ou tacrolimos), um corticosteróide (prednisona) e um inibidor da síntese de purinas (micofenolato mofetil ou micofenolato sódico) ou azatioprina. Como tratamento da rejeição aguda, esses pacientes receberam solumedrol 1g EV e/ou anticorpos anti-lifocíticos poli ou monoclonais. Os pacientes com rejeição aguda sobreposta à nefropatia crônica do enxerto (dois no grupo RACNV e nove no grupo RAV) não estavam em uso de imunossupressores ou recebiam somente prednisona em baixas doses. (tabela 1).

Tabela 1: Idade, sexo, tipo de doador, tempo até a realização da enxertectomia e número de pacientes que receberam tratamento específico para rejeição aguda:

\begin{tabular}{llllll}
\hline Grupo & $\begin{array}{l}\text { Idade do } \\
\text { receptor } \\
\text { (média } \\
\mathbf{\pm D P})\end{array}$ & $\begin{array}{l}\text { Receptores } \\
\text { do sexo } \\
\text { masculino } \\
\mathbf{n}(\%)\end{array}$ & $\begin{array}{l}\text { Doador } \\
\text { falecido } \\
\mathbf{n}(\%)\end{array}$ & $\begin{array}{l}\text { Tempo até } \\
\text { a enxertec- } \\
\text { tomia } \\
\text { em dias } \\
\text { (medianas) }\end{array}$ & $\begin{array}{l}\text { Pacientes } \\
\text { que } \\
\text { receberam } \\
\text { tratamento } \\
\text { específico } \\
\text { para } \\
\text { rejeição } \\
\text { aguda } \\
\mathbf{n}(\%)\end{array}$ \\
\hline PCNI & $34.2 \pm 11.9$ & $2(40 \%)$ & $3(60 \%)$ & 14 & - \\
RACNV & $35.6 \pm 11.4^{*}$ & $3(60 \%) \ddagger$ & $2(40 \%)$ & $281 \S$ & $2(40 \%)$ \\
RAV & $36.7 \pm 11.1 \dagger$ & $9(64 \%) \ddagger$ & $7(50 \%)$ & $1189 \|$ & $5(35 \%) \uparrow$ \\
\hline
\end{tabular}

PCNI- perda de causa não imune; RACNV - rejeição aguda não vascular $R A V$ - rejeição aguda vascular

* $p=0.854$ (para PCNI e RACNV por teste $t$ de Student)

t, $p=0.675$ (PCNI e RAV por teste $t$ de Student)

‡ $p=1$ (PCNI e RACNV e PCNI e RAV por teste exato de Fisher)

$\S p=0.032$ (PCNI e RACNV por teste $t$ de Student)

|| $p=0.021$ (PCNI e RAV por teste $t$ de Student)

I $p=1$ (RACNV e RAV por teste exato de Fisher)

\section{Expressão de moléculas relacionadas à resposta imune citotóxica}

Para análise da resposta imune citotóxica foram utilizadas as seguintes moléculas: granzima B, perforina e IFN- $\gamma$. A expressão do mRNA dessas moléculas foi maior em pacientes com diagnóstico de rejeição. Especificamente, os valores das medianas da expressão do mRNA da granzima B foram 3 para o grupo controle e 1282,9 para o grupo com rejeição aguda $(\mathrm{p}=0,003)$; da perforina 7,4 para o grupo controle e 567,3 para o grupo com rejeição $(p=0,013)$ e de IFN- $\gamma 49,6$ para o controle e 249,3 para a rejeição $(p=0,034)$ (figura 1). Quando separamos os grupos de acordo com a gravidade da rejeição, as medianas de expressão dos transcritos encontradas foram: granzima B - 3 para o grupo PCNI, 369,6 para RACNV e 1305,1 para RAV ( $\mathrm{p}=0,003$ para $\mathrm{PCNI}$ e RAV); perforina $-7,4$ para PCNI, 403,5 para RACNV e 797,8 para RAV ( $\mathrm{p}=0,008$ para $\mathrm{PCNI}$ e RAV) e IFN- $\gamma-49,6$ para PCNI, 31,4 para RACNV e 435,5 para RAV ( $p=0,008$ para PCNI e RAV) (figura 2).

Como alguns pacientes dos grupos com rejeição aguda apresentavam nefropatia crônica do enxerto concomitante (2 no grupo RACNV e 9 no grupo RAV), as amostras foram separadas de acordo com a presença ou ausência de nefropatia crônica (figuras 3 e 4). Os
Figura 1. Gráfico tipo box plot demonstrando os valores dos percentis 10, 25, 50 (mediana), 75 e 90 para os níveis de mRNA das moléculas reguladoras Tim-3, galectina-9 e FOXP3 e das moléculas pró-inflamatórias granzima $B$, perforina e IFN- $\gamma$. Para todas as moléculas estudadas, a diferença entre o grupo controle e rejeição apresentou significância estatística $(p<0,05)$.
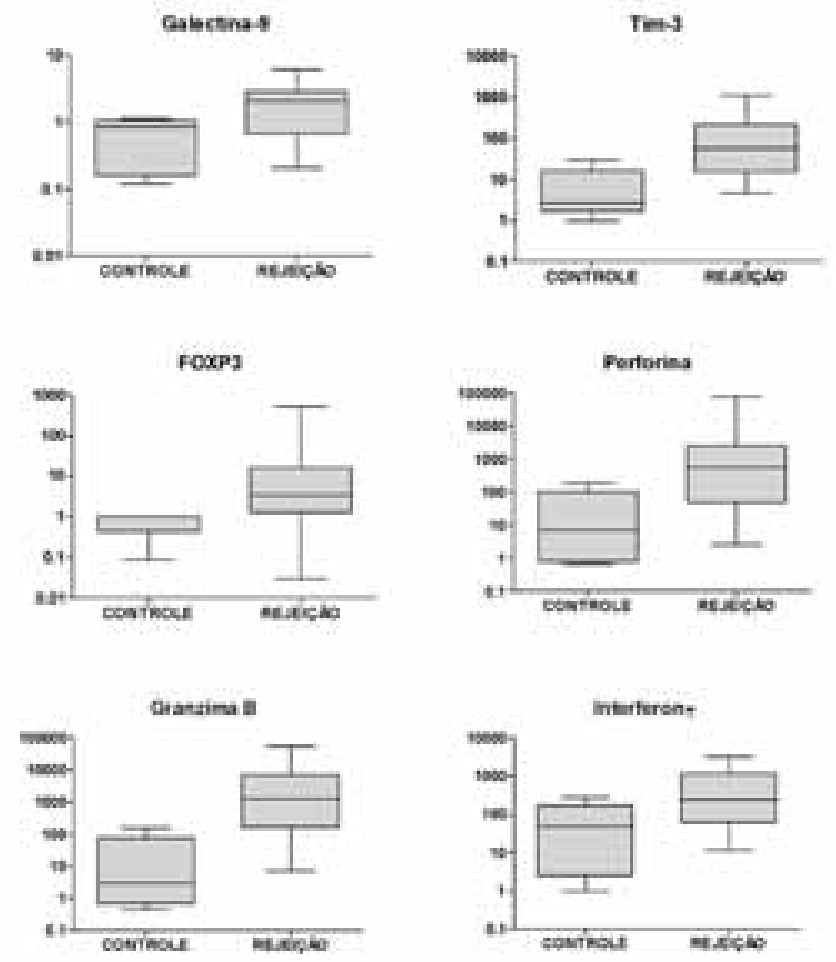

valores das medianas dos transcritos obtidos nas amostras sem evidência de nefropatia crônica foram: 3 para o grupo controle e 173,6 para o grupo com rejeição aguda de granzima $\mathrm{B}(\mathrm{p}=0,02)$; 7,4 para o grupo controle e 50,1 para o grupo com rejeição aguda da perforina $(p=0,17)$ e 49,6 para o controle e 61,5 para o grupo de rejeição de IFN- $\gamma(p=0,27)$. Quando os grupos foram separados de acordo com a gravidade da rejeição, as medianas de expressão dos transcritos encontrados foram: granzima $\mathrm{B}-3$ para o grupo PCNI, 10,9 para RACNV e 206,8 para RAV; perforina - 7,4 para PCNI, 4,9 para RACNV e 60,4 para RAV e IFN- $\gamma-49,6$ para PCNI, 23, 2 para RACNV e 83,9 para RAV. Nas amostras com evidência de nefropatia crônica do enxerto concomitante com rejeição aguda, os valores encontrados das medianas foram: 3 para o grupo controle e 2169,2 para o grupo com rejeição aguda de granzima $B(p=0,002)$; 7,4 para o grupo controle e 896,3 para o grupo com rejeição aguda da perforina ( $\mathrm{p}=0,001)$ e 49,6 para o controle e 465,3 para o grupo com rejeição de IFN- $\gamma(\mathrm{p}=0,01)$. Novamente, essas amostras foram separadas de acordo com a gravidade da rejeição e as medianas encontradas de expressão dos transcritos foram: granzima B - 3 para o grupo PCNI, 2450,5 para RACNV e 2169,2 para RAV; perforina - 7,4 para PCNI, 742,3 para RACNV e 1408,3 para RAV e IFN- $\gamma-49,6$ para PCNI, 191,9 para RACNV e 786,7 para RAV.

\section{Expressão de moléculas relacionadas à resposta imune reguladora}

Foi estudada a expressão relativa do mRNA das moléculas Tim-3, galectina-9 e FOXP3 para a análise da resposta imune 
Figura 2. Gráfico tipo box plot demonstrando os valores dos percentis 10, 25, 50 (mediana), 75 e 90 para os níveis de mRNA das moléculas reguladoras Tim-3, galectina-9 e FOXP3 e das moléculas pró-inflamatórias granzima $B$, perforina e IFN- $\gamma$. A diferença entre as medianas dos grupos perda de causa não imune (PCNI) e rejeição vascular (RAV) para todas as moléculas estudadas alcançou significância estatística.
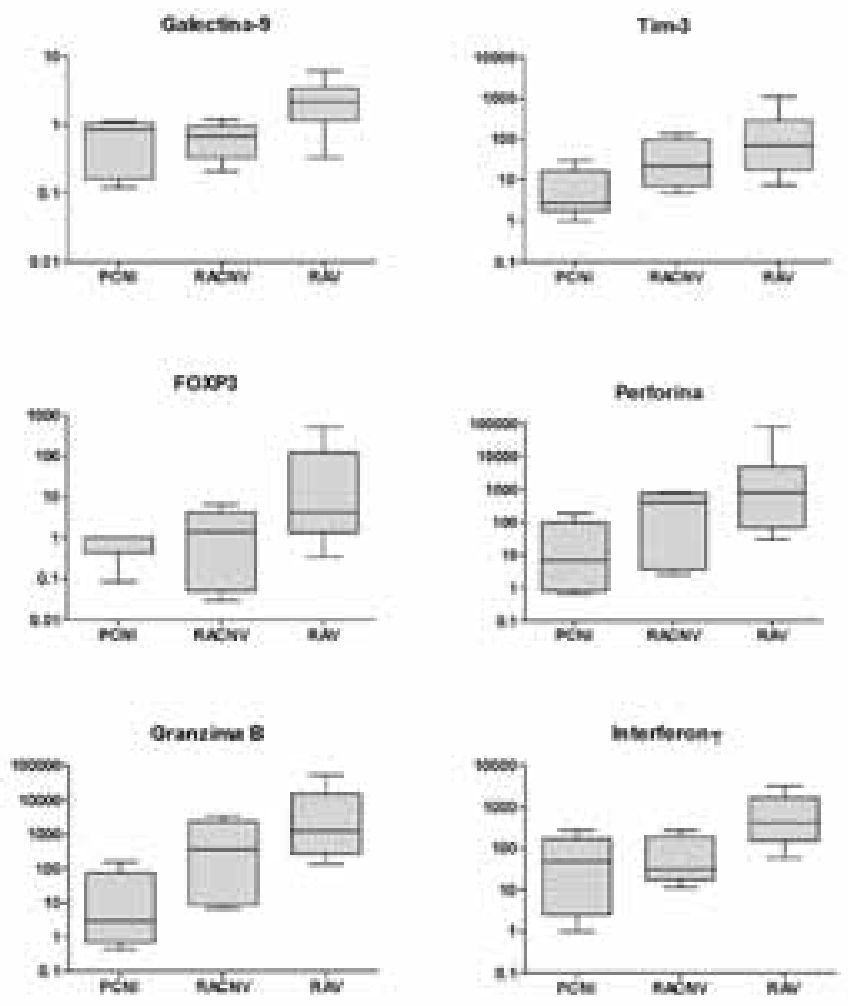

reguladora. De maneira semelhante à demonstrada para resposta imune citotóxica, a expressão do mRNA dessas moléculas foi maior em produtos de enxertectomia com diagnóstico de rejeição aguda. As medianas da expressão de Tim-3 foram: 2,7 para o grupo controle e 57 para o grupo com rejeição aguda $(\mathrm{p}=0,007)$, de galectina-9 0,8 para o controle e 2 para rejeição aguda $(\mathrm{p}=0,065)$ e de FOXP3 1 para o controle e 3,5 para rejeição $(p=0,019)$ (figura 1). Igualmente, quando os grupos foram separados de acordo com a gravidade da rejeição, os níveis de expressão das moléculas reguladoras foram maiores em rejeições mais graves. Os valores das medianas de Tim-3 foram 2,7 para o grupo PCNI, 22 para RACNV e 68,9 para RAC ( $\mathrm{p}=0,008$ para PCNI e RAV) e de Galectina-9 0,8 para PCNI, 0,6 para RACNV e 2,1 para RAV ( $p=0,024$ para PCNI e RAV). Para FOXP3 as medianas foram 1 para PCNI, 1,4 para RACNV e 4,2 para RAV ( $p=0,005$ para PCNI e RAV) (figura 2).

Essas amostras também foram separadas de acordo com a presença ou ausência de nefropatia crônica do enxerto (figura 3 e 4). As medianas encontradas nas amostras sem evidência de nefropatia crônica foram: 2,7 para o grupo controle e 17,7 para o grupo com rejeição aguda de Tim-3 ( $\mathrm{p}=0,06) ; 0,8$ para o grupo controle e 2,1 para o grupo com rejeição aguda de galectina- $9(\mathrm{p}=0,12)$ e 1 para o controle e 1,9 para o grupo rejeição de FOXP3 $(\mathrm{p}=0,12)$. Quando os grupos foram separados de acordo com a gravidade da rejeição,
Figura 3. Gráfico tipo box plot demonstrando os valores dos percentis 10, 25, 50 (mediana), 75 e 90 para os niveis de mRNA das moléculas reguladoras Tim-3, galectina-9 e FOXP3 e das moléculas pró-inflamatórias granzima $B$, perforina e IFN- $\gamma$ em amostras sem evidência de nefropatia crônica do enxerto concomitante. Para todas as moléculas estudadas, a diferença entre o grupo controle e rejeição apresentou significância estatística $(p<0,05)$
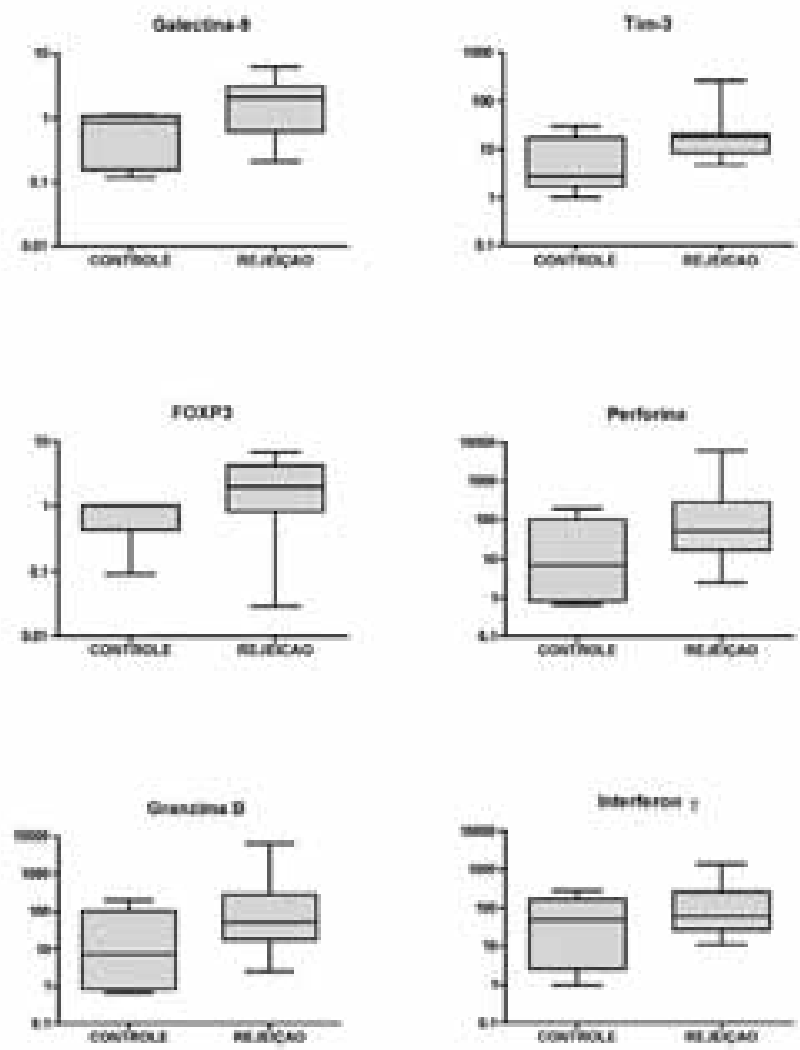

as medianas de expressão dos transcritos foram: Tim-3 - 2,7 para o grupo PCNI, 9,4 para RACNV e 19,3 para RAV; galectina-9 - 0,8 para PCNI, 0,4 para RACNV e 2,9 para RAV e FOXP3 - 1 para PCNI, 1,9 para RACNV e 2 para RAV. Nas amostras com evidência de nefropatia crônica do enxerto concomitante com rejeição aguda, os valores das medianas foram: 2,7 para o grupo controle e 145,2 para o grupo com rejeição aguda de Tim-3 ( $\mathrm{p}=0,001)$; 0,8 para o grupo controle e 1,3 para o grupo com rejeição aguda de galetina-9 $(\mathrm{p}=0,12)$ e 1 para o controle e 13,1 para o grupo rejeição de FOXP3 $(p=0,01)$. De maneira semelhante, essas amostras foram separadas de acordo com a gravidade da rejeição, e os valores das medianas de expressão dos transcritos foram: Tim-3 - 2,7 para o grupo PCNI, 99,7 para RACNV e 163,1 para RAV; galectina-9 - 0,8 para PCNI, 0,9 para RACNV e 1,8 para RAV e FOXP3 1 para PCNI, 0,7 para RACNV e 49,4 para RAV.

\section{Correlação entre a expressão de Tim-3 e galectina-9}

As análises dessas duas moléculas demonstram uma correlação positiva entre os níveis de expressão da galectina-9 e de Tim-3 $(r=0,526 ; p=0,016)$. Também existiu correlação entre a expressão de Tim-3 e de moléculas pró-inflamatórias (figura 5). Não houve correlação entre os níveis de expressão de galectina-9 e IFN- $\gamma$. 
Figura 4. Gráfico tipo box plot demonstrando os valores dos percentis 10, 25, 50 (mediana), 75 e 90 para os níveis de mRNA das moléculas reguladoras Tim-3, galectina-9 e FOXP3 e das moléculas pró-inflamatórias granzima $B$, perforina e IFN- $\gamma$ em amostras com evidência de nefropatia crônica do enxerto concomitante. Para todas as moléculas estudadas, a diferença entre o grupo controle e rejeição apresentou significância estatística $(p<0,05)$
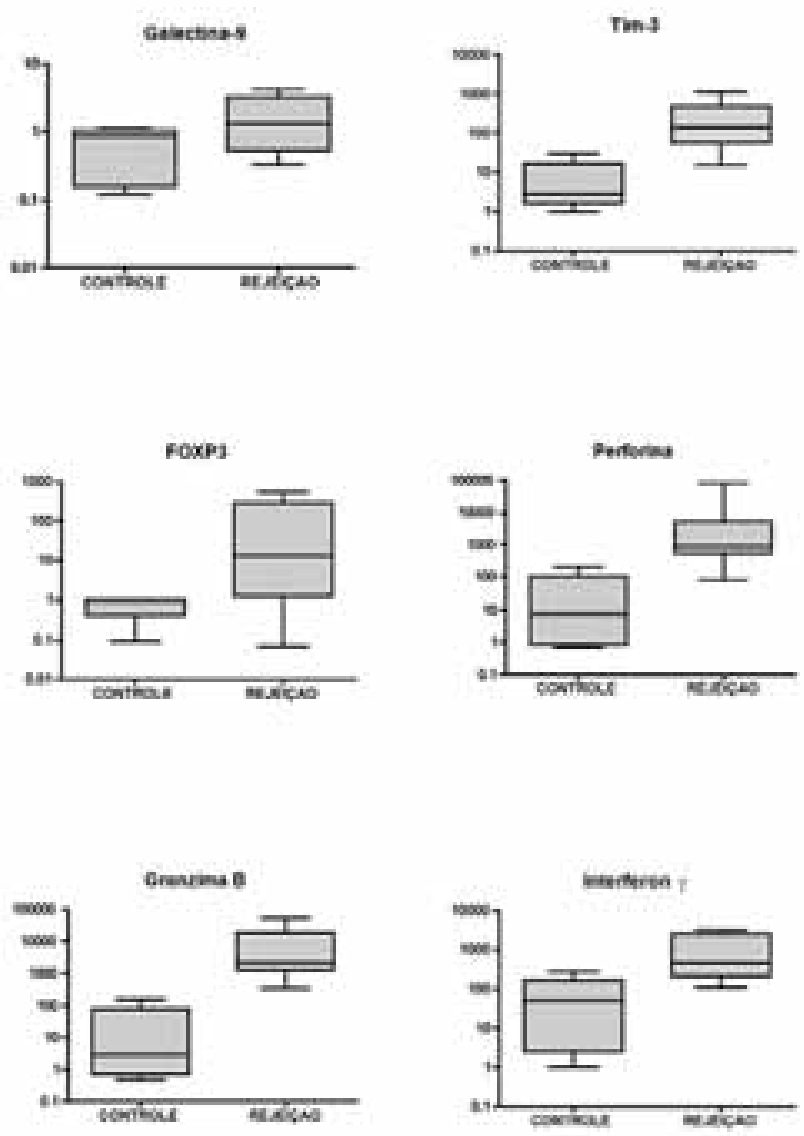

\section{DISCUSSÃO}

A resposta imune é um processo dinâmico, e os fatores próinflamatórios são contrabalanceados por mecanismos reguladores, os quais são capazes de evitar uma resposta exagerada a um antígeno estranho ou contra um antígeno próprio. Nossa hipótese é que essa homeostase também é mantida no contexto do transplante de órgãos, e que a rejeição aguda ocorre quando esse equilíbrio é quebrado, favorecendo a resposta pró-inflamatória.

A presença de moléculas relacionadas à resposta imune citotóxica já foi demonstrada em amostras de tecido de enxertos renais, ${ }^{22}$ em leucócitos de sangue periférico ${ }^{23}$ e em urina ${ }^{24,25}$ de pacientes transplantados renais, e houve concordância entre esses achados e o diagnóstico de rejeição aguda. Transcritos relacionados à resposta imune reguladora também foram descritos. A presença de FOXP3 foi demonstrada em urina de pacientes com rejeição aguda, ${ }^{26}$ assim como em biópsias ${ }^{27,28}$ e em produtos de enxertectomia renais, ${ }^{19}$ porém nem todos os estudos foram capazes de correlacionar esse achado a uma melhor evolução. A detecção de FOXP3 é fortemente sugestiva da presença de Treg, apesar dessa molécula também estar presente em células ativadas incapazes de regular a resposta imune. ${ }^{17}$
Figura 5: Correlação entre os níveis de mRNA de Tim-3 com seu ligante, a galectina-9, e com as moléculas pró-inflamatórias IFN- $\gamma$, granzima $B$ e perforina.
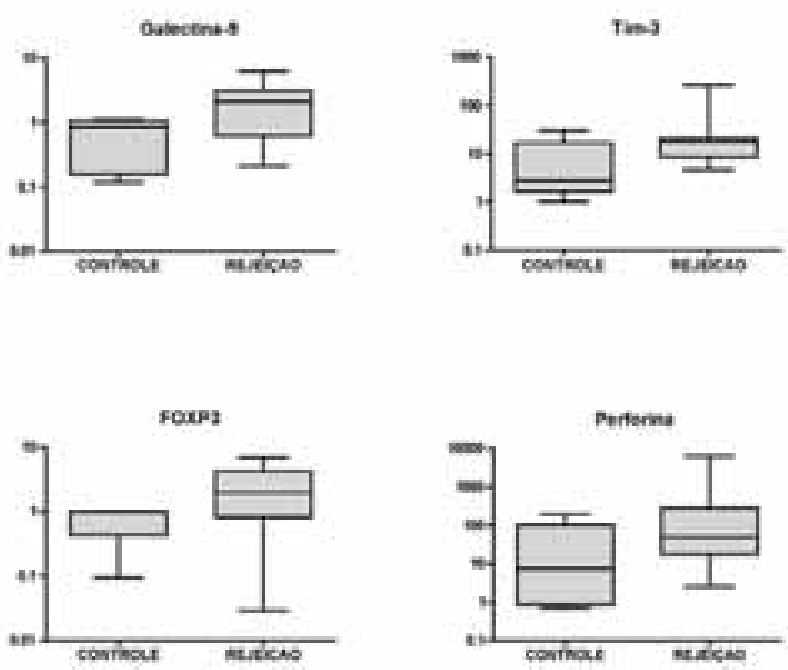

O Tim-3 também já foi detectado em urina de pacientes transplantados durante rejeição aguda ${ }^{29}$ e também em produtos de enxertectomia renal. ${ }^{20} \mathrm{~A}$ participação dessa molécula na regulação da resposta Th1 foi inicialmente determinada em um modelo experimental de encefalomielite. ${ }^{30} \mathrm{O}$ bloqueio do Tim-3 nesse modelo resultou em piora dos padrões clínicos e patológicos da doença.

A identificação de moléculas reguladoras da resposta imune não se traduz necessariamente em ganho funcional. Sendo a galectina-9 o ligante do Tim-3, a identificação da primeira corrobora com uma maior função reguladora da resposta Th1. A deteç̧ão de galectina-9 foi maior em enxertos com rejeições mais graves, o que pode ser uma evidência de que o desenvolvimento dessa função reguladora não é suficiente para evitar uma resposta citotóxica agressiva ao enxerto que resulte em perda do órgão. Apesar da expressão da galectina-9 poder ser induzida pelo IFN- $\gamma$, no presente estudo não houve correlação entre os níveis dessas duas moléculas.

A interpretação dos resultados deste estudo requer alguns cuidados. A classificação de rejeição aguda vascular e não vascular foi baseada exclusivamente em critérios histo-morfológicos, não tendo sido realizada análise imunohistoquímica para presença de $\mathrm{C} 4 \mathrm{~d}$, atualmente o marcador mais fidedigno do envolvimento de anticorpos no processo de rejeição. ${ }^{31}$ Portanto, tanto o envolvimento da resposta imune humoral no processo de rejeição aguda vascular quanto sua relação com as moléculas estudadas não puderam ser avaliados no presente estudo.

Como grupo controle, foram utilizadas amostras de rim não funcionante em decorrência de isquemia aguda (trombose arterial e/ ou venosa). A isquemia, per se, é capaz de desencadear uma resposta imune. Além disso, o tempo decorrente até a retirada do enxerto nesses pacientes foi significantemente menor quando comparado aos grupos RANV e RAV. Conseqüentemente, o tempo de exposição dos aloantígenos ao sistema imune do receptor foi menor, o que pode influenciar tanto a resposta imune citopática quanto a regulatória. De maneira semelhante, esse grupo não recebeu 
tratamento imunossupressor específico para rejeição aguda, e não havia evidência de nefropatia crônica do enxerto nessas amostras. A influência desses dois outros fatores no desenvolvimento da resposta imunológica deve ser considerada. As amostras obtidas de rim nãofuncionante em decorrência de isquemia aguda foram escolhidas como grupo controle, pois dois dos transcritos de interesse, FOXP3 e Galectina-9, não foram detectados em amostras de tecido normal obtidas de biópsias protocolares, possivelmente devido a menor quantidade de material disponível para o estudo, se comparando com as amostras obtidas de produtos de enxertectomias.

Outra possível fonte de viés no presente estudo é a presença de nefropatia crônica do enxerto em um numero significativo de amostras (2 do grupo RACNV e 9 do grupo RAV). A nefropatia crônica do enxerto envolve alterações tanto de causas nãoimunológicas quanto imunológicas; ${ }^{32}$ portanto, sua influência sobre o desenvolvimento tanto da resposta citotóxica quanto da resposta imuno-reguladora deve ser considerada. De fato, quando analisamos separadamente as amostras de acordo com a presença ou ausência de nefropatia crônica do enxerto, a significância estatística não se manteve para todas as moléculas.

\section{CONCLUSÃO}

Neste estudo, nós demonstramos que o ligante de Tim-3, a Galectina-9, é encontrada em produtos de enxertectomia renal com diagnóstico de rejeição, e que sua expressão se relaciona com a gravidade da mesma. Houve correlação entre os níveis de Tim-3 e galectina-9, sugerindo aumento da função reguladora da resposta Th1 durante a resposta imune citotóxica. No momento, mais estudos são necessários para esclarecer os mecanismos envolvidos nessa regulação, e, mais importante, quais desses mecanismos podem ser capazes de bloquear um episódio de rejeição aguda ao órgão transplantado.

\section{ABSTRACT}

Introduction: Tim-3 is a Th1 lymphocytes membrane protein with inhibitory function. Its ligand, the galectin-9, was recently identified, and it is expressed in some lymphocytes population. In addition, endothelial cells and fibroblasts can also express the galectin-9, according to the local cytokine milieu. These molecules, together with the CD4+CD25+ T lymphocytes, act as important regulatory tools to the immune system. FOXP3 is a transcription factor associated to the regulatory CD4+CD25+ T cells. Purpose: To assess the expression of these immunoregulator molecules inside kidney allografts during acute rejection episodes. Methods: By using a quantitative polymerase chain reaction assay, we measured the levels of the RNA messenger for Galectin-9, Tim-3 and FOXP3, in 24 sampling attained from allograft nephrectomy for acute nonvascular rejection $(n=5)$, acute vascular rejection ( $n=14)$ or loss due to a nonimmune cause ( $n=5$, as control). The granzyme B molecules, perforin and interferon-gamma were also analyzed, since they represent host-driven immune response. Results: Median mRNA levels of all immunoregulator as well as cytolytic molecules correlated to the severity of the rejection: $\mathrm{p}=0.024$ for galectin-9, $\mathrm{p}=0.008$ for Tim3, $\mathrm{p}=0.005$ for FOXP3, $\mathrm{p}=0.008$ for perforin and interferon-gamma; and $\mathrm{p}=0.003$ for granzim $\mathrm{B}$. Conclusion: Among all the studied molecules, mRNA levels were higher inside allografts which presented more severe rejection. This data suggest the immune response is a dynamic process, and it involves both cytopathic and regulatory mechanisms. The acute rejection episode could be consequence of a disproportion in such response.

Keywords: Kidney Transplantation, Graft Rejection, Immune Tolerance

\section{REFERÊNCIAS}

1. Halloran PF. Immunosuppressive drugs for kidney transplantation. N Engl J Med. 2004;351(26):2715-29.

2. Marleau AM, Sarvetnick N. T cell homeostasis in tolerance and immunity. J Leukoc Biol. 2005;78(3):575-84

3. Kamradt T, Mitchison NA. Tolerance and autoimmunity. N Engl J Med 2001;344(9):655-64.

4. Monney L, Sabatos CA, Gaglia JL, Ryu A, Waldner H, Chernova T, et al. Th1specific cell surface protein Tim-3 regulates macrophage activation and severity of an autoimmune disease. Nature. 2002;415:536-41.

5. Rabinovich GA, Liu FT, Hirashima M, Anderson A. An emerging role for galectins in tuning the immune response: lessons from experimental models of inflammatory disease, autoimmunity and cancer. Scand J Immunol. 2007;66(2-3):143-58

6. Ilarregui JM, Bianco GA, Toscano MA, Rabinovich GA. The coming of age of galectins as immunomodulatory agents: impact of these carbohydrate binding proteins in T cell physiology and chronic inflammatory disorders. Ann Rheum Dis. 2005;64 Suppl 4:96-103
7. Tashiro K, Sakata K, Hirashima M, Hayashi H. The regulation of tissue eosinophilia. III. In vitro production of eosinophil-directed chemotactic inhibitory factor by $\mathrm{T}$ lymphocytes of Freund's complete adjuvant-treated guinea-pigs. Immunology. 1985;55:115-24.

8. Imaizumi T, Kumagai M, Sasaki N, Kurotaki H, Mori F, Seki M, et al. Interferongamma stimulates the expression of galectin-9 in cultured human endothelial cells. J Leukoc Biol. 2002;72(3):486-91.

9. Asakura H, Kashio Y, Nakamura K, Seki M, Dai S, Shirato Y, et al. Selective eosinophil adhesion to fibroblast via IFN-gamma-induced galectin-9. J Immunol. 2002;169(10):5912-8.

10. Zhu C, Anderson AC, Schubart A, Xiong H, Imitola J, Khoury SJ, et al. The Tim-3 ligand galectin-9 negatively regulates $\mathrm{T}$ helper type 1 immunity. Nat Immunol. 2005;6(12):1245-52.

11. Sakaguchi S. Naturally arising Foxp3-expressing CD25+CD4+ regulatory T cells in immunological tolerance to self and non-self. Nat Immunol. 2005;6(4):345-52.

12. Sakaguchi S, Powrie F. Emerging challenges in regulatory T cell function and biology. Science. 2007;317(5838):627-9. 
13. Chen W, Jin W, Hardegen N, Lei KJ, Li L, Marinos N, et al. Conversion of peripheral CD4+CD25- naive T cells to CD4+CD25+ regulatory T cells by TGF-beta induction of transcription factor Foxp3. J. Exp. Med. 2003;198:1875-1886.

14. Selvaraj RK, Geiger TL. A kinetic and dynamic analysis of Foxp3 induced in T cells by TGF-beta. J Immunol. 2007;178(12):7667-77.

15. Chai JG, Xue SA, Coe D, Addey C, Bartok I, Scott D, et al. Regulatory T cells, derived from naïve CD4+CD25- T cells by in vitro Foxp3 gene transfer, can induce transplantation tolerance. Transplantation 2005;79:1310-6.

16. Wan YY, Flavell RA. Regulatory T-cell functions are subverted and converted owing to attenuated Foxp3 expression. Nature. 2007;445(7129):766-70.

17. Tran DQ, Ramsey H, Shevach EM. Induction of FOXP3 expression in naive human CD4+FOXP3- T cells by T cell receptor stimulation is TGF\{beta\}-dependent but does not confer a regulatory phenotype. Blood. 2007 Disponível em: URL: http:// bloodjournal.hematologylibrary.org.

18. Graca L, Cobbold SP, Waldmann H: Identification of regulatory T cells in tolerated allografts. J Exp Med. 2002;195:1641-4.

19. Naka EL, Ponciano VC, Rangel EB, Cenedeze MA, Pacheco-Silva A, Camara NO. FOXP3-positive regulatory cells inside the allograft and the correlation with rejection. Transplant Proc. 2006;38(10):3202-4.

20. Ponciano VC, Renesto PG, Nogueira E, Rangel EB, Cenedeze MA, Franco MF, et al. Tim-3 expression in human kidney allografts. Transpl Immunol.2007;17(3):215-22.

21. Racusen LC, Solez K, Colvin RB, Bonsib SM, Castro MC, Cavallo T, et al. The Banff 97 working classification of renal allograft pathology. Kidney Int 1999;55(2):713-23.

22. Strehlau J, Pavlakis M, Lipman M, Shapiro M, Vasconcellos L, Harmon W, et al Quantitative detection of immune activation transcripts as a diagnostic tool in kidney transplantation. Proc Natl Acad Sci U S A. 1997;94(2):695-700.

23. Vasconcellos LM, Schachter AD, Zheng XX, Vasconcellos LH, Shapiro M, Harmon WE, et al. Cytotoxic lymphocyte gene expression in peripheral blood leukocytes correlates with rejecting renal allografts. Transplantation 1998;66(5):562-6.
24. Li B, Hartono C, Ding R, Sharma VK, Ramaswamy R, Qian B, et al. Noninvasive diagnosis of renal-allograft rejection by measurement of messenger RNA for perforin and granzyme B in urine. N Engl J Med. 2001;344(13):947-54.

25. Galante NZ, Câmara NO, Kallas EG, Salomão R, Pacheco-Silva A, Medina-Pestana JO. Noninvasive immune monitoring assessed by flow cytometry and real time RT-PCR in urine of renal transplantation recipients. Transpl Immunol. 2006;16(2):73-80.

26. Muthukumar T, Dadhania D, Ding R, Snopkowski C, Naqvi R, Lee JB, et al. Messenger RNA for FOXP3 in the urine of renal-allograft recipients. N Engl J Med. 2005;353(22):2342-51.

27. Velthuis JH, Mol WM, Weimar W, Baan CC. CD4+CD25bright+ regulatory T cells can mediate donor nonreactivity in long-term immunosuppressed kidney allograft patients. Am J Transplant. 2006;6(12):2955-64.

28. Grimbert P, Mansour H, Desvaux D, Roudot-Thoraval F, Audard V, Dahan K, et al. The regulatory/cytotoxic graft-infiltrating $\mathrm{T}$ cells differentiate renal allograft borderline change from acute rejection. Transplantation. 2007;83(3):341-6

29. Renesto PG, Ponciano VC, Cenedeze MA, Saraiva Câmara NO, Pacheco-Silva A. High expression of Tim-3 mRNA in urinary cells from kidney transplant recipients with acute rejection. Am J Transplant. 2007;7(6):1661-5.

30. Monney L, Sabatos CA, Gaglia JL, Ryu A, Waldner H, Chernova T, et al. Th-1 specific cell surface protein TIM-3 regulates macrophage activation and severity of an autoimmune disease. Nature. 2002;415: 536-541.

31. Böhmig GA, Exner M, Habicht A, Schillinger M, Lang U, Kletzmayr J, et al. Capillary C4d deposition in kidney allografts: a specific marker of alloantibody-dependent graft injury. J Am Soc Nephrol. 2002;13(4):1091-9.

32. Pascual M, Theruvath T, Kawai T, Tolkoff-Rubin N, Cosimi AB. Strategies to improve long-term outcomes after renal transplantation. N Engl J Med. 2002;346(8):580-90. 